\title{
White Innocence: Paradoxes of colonialism and race
}

\author{
Gloria Wekker. 2016. White InNocence: Paradoxes of colonialism and race Durham: Duke University \\ PRESS, 240 PP. ISBN 9780822360759
}

\section{Melina Gaona}

CONiCet, Centro de Estudios de Historia, Cultura y Comunicación Universidad Nacional de Quilmes. Quilmes, ARGENTINA

ORCID ID: 0000-0002-2960-5957

CORREO ELECTRÓNICO: melina.d.gaona@gmail.com

Gloria Wekker es una antropóloga sociocultural de origen holandés afrosurinamés; profesora emérita de Estudios de Género y Etnicidad en la Universidad de Utrecht (Holanda). Su extensa labor antirracista e interseccional fue fundamental para abrir campos completos de estudio en distintas regiones de Europa, y para comprender la permanente vigencia de los legados coloniales en territorios imperialistas. Eso, y sus valiosos aportes en su rol como asesora política y consultora, la convierten en una de las figuras políticas y académicas holandesas más influyentes de las últimas décadas.

El libro de Wekker aporta principalmente a la rama de los estudios sociales que indagan en la construcción social de la blanquitud. La autora lo hace desde una perspectiva de género e interseccional abocándose al análisis de lo que define como el "archivo cultural” de la nación. Wekker considera que la raza, la racialización y el racismo están en el corazón de Holanda, pero aún esto es negado, rechazado y eludido por medio de diferentes repertorios de discurso. La autora presenta una reserva de actitudes y sentimientos no admitidos que están basados en 400 años de dominio imperial, que hacen de base de la violencia, el racismo y la opresión en una sociedad multiétnica.

Al comprometerse críticamente con temas que han sido invisibilizados en la cultura holandesa-que, de acuerdo con la autora, desconoce e históricamente ha desconocido su legado colonial-, explora las paradojas nacionales entre un sentimiento de supuesta integridad ética y una historia tan fuerte de imperialismo y violencia.

Wekker se centra en las contradicciones en torno a los discursos y narrativas dominantes holandeses a partir de un análisis poscolonial e intersectorial. Así, es capaz de construir su trabajo como un conjunto denso y crítico de experiencias personales, entrevistas, percepciones sobre la industria cultural, las estructuras organizativas y el conocimiento cultural y académico. Resulta un aporte de escritura interesante para seguir el proceso de desenvolvimiento teórico anclado en ejemplos prácticos a partir de etnografías de estas características.

El título del libro, La inocencia blanca: paradojas del colonialismo y la raza, se circunscribe a la noción por la cual la autorrepresentación blanca holandesa dominante suele poner a los habitantes de los Países Bajos como libres de todo racismo y siendo una pequeña nación inherentemente ética, ajena a conflictos internos del resto de Europa. De acuerdo con la autora, esta noción de inocencia implica no saber, y no querer saber (una "epistemología de la ignorancia", p. 17), la magnitud con la que verdaderamente opera la lógica racista en todas las escalas sociales. Asimismo, esta inocencia se sostiene sobre todo a partir de la negación del privilegio propio, de la construcción de una sensación de mayor capacidad en relación con otros, y del desconocimiento de la violencia esgrimida contra distintas minorías internas. doi: $10.34096 /$ cas.i50.5357

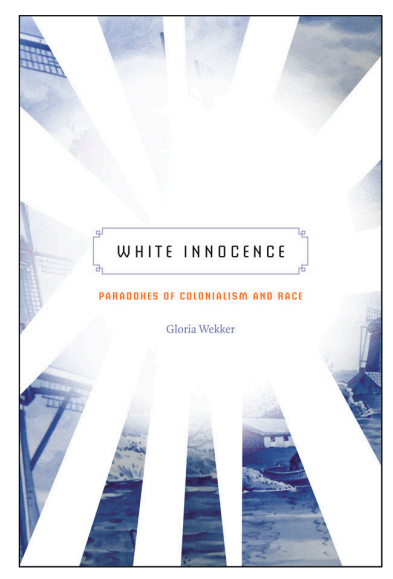


La autora transita los cinco capítulos del libro, más una coda, con distintos ejemplos empíricos como disparadores de los debates que pretende sostener. Para ello, recurre a este "archivo cultural" construido, un término retomado de Edward Said (1993), que utiliza como paraguas conceptual bajo el cual explora diferentes formas de conocer -y de estructuraractitudes y sentimientos. En este caso, las formas en que una historia racial imperial sigue sustentando los modos dominantes de conocer e interpretar, y cómo ello define no solo la autorrepresentación dominante, sino también los modos de actuar en las organizaciones burocráticas y sociales, las políticas públicas, los estudios académicos, los productos mediáticos y culturales, etcétera. El archivo cultural de Wekker es conceptualmente similar a nociones como el "depósito de la memoria" (Stoler, 2009), como el habitus (Bourdieu, 1977), como las "estructuras del sentir" (Williams, 1977), o como los regímenes de verdad. Todos estos términos son utilizados por la propia autora.

El conjunto del texto puede resultar útil para interpretar procesos en el presente, sobre todo entre sociedades que no están basadas en un fuerte reconocimiento de la diferencia como parte de los mapas multiculturales actuales, sino que se sostienen sobre todo a partir de discursos (y operaciones) asimilacionistas. Este tipo de construcción de la nación no se restringe a las naciones europeas.

De esta manera, muestra cómo una sociedad asimilacionista como la holandesa niega actitudes parciales basadas en la raza y la etnia pero en realidad actúa en consecuencia con ellas. Así, el racismo se convierte en un criterio de división silencioso y significativo del sentido común y el humor cotidiano. Algunas prácticas señaladas por la autora refieren al modo en el que las políticas gubernamentales se han definido por asimilación y han sentado qué parte de la población es la que se ajusta e integra y cuál es la norma. Con ello, sentando las implicancias de lo que supone entender la "integración exitosa" de los migrantes a partir de la interiorización de valores locales. Como otra parte de esa orientación racista silenciosa que opera permanentemente, Wekker expone la completa esferización burocrática departamental de las diferencias por género y sexualidad, raza, etnia, nacionalidad como factores separables, así como la división del trabajo en el ámbito académico de los estudios de género a partir de una división racializada y una marcada posicionalidad señalada como "nosotros" los estudiamos a "ellos" (p. 68). De acuerdo con la evidencia, esto deviene además en la ausencia total en la currícula educativa de la presencia imperial en el mundo y el borramiento de la diáspora histórica de comunidades poscoloniales a la nación holandesa.

Una lectura crítica puede encontrar algunas flaquezas en las estrategias argumentativas por algunas redundancias en los argumentos con el fin de sostener lo propuesto. Sin embargo, en tanto los estudios raciales resultan históricamente volcados a señalar aquello que se reconoce como diferencia, y muy pocas veces se han hecho estudios sistemáticos desde la interseccionalidad sobre aquellos construidos como norma, La Inocencia blanca: paradojas del colonialismo y la raza se convierte en un buen antecedente para pensar la estructuración y la construcción de los grupos de poder a partir de la expansión de los sentidos comunes y la total difuminación y negación de las ideologías dominantes.

\section{Referencias bibliográficas}

» Bourdieu, P. (1977). Outline of a Theory of Practice. Cambridge: Cambridge University Press.

"Said, E. (1993). Culture and imperialism. Nueva York: Vintage Books.

»Stoler, A. (2009). Along the archival grain: Epistemic anxieties and colonial common sense. Nueva Jersey: Princeton University Press. 